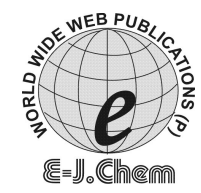

http://www.e-journals.net

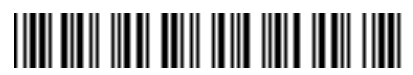

ISSN: 0973-4945; CODEN ECJHAO

E-Journal of Chemistry

Vol. 4, No. 4, pp. 502-509, October 2007

\title{
Determination of Quantum Yield for the Photochemical Decomposition of Dichloramine-B and Dibromamine-B in Aqueous Acetic Acid Medium
}

\author{
K. N. MOHANA*, N. PRASAD and P. M. RAMADAS BHANDARKAR \\ Department of Studies in Chemistry, \\ University of Mysore, Manasagangotri, \\ Mysore - 570 006, India. \\ knmsvp@yahoo.com
}

Received 14 April 2007; Accepted 30 May 2007

\begin{abstract}
The photolysis of dihaloamines $\left(\mathrm{RNX}_{2}\right)$, viz., dichloramine-B (DCB) and dibromamine-B (DBB) in aqueous acetic acid $(1: 1 \mathrm{v} / \mathrm{v})$ solutions has been studied with the UV light source $(\lambda=2537 \AA)$. The experimental rate law obtained is $-\mathrm{d}\left[\mathrm{RNX}_{2}\right] / \mathrm{dt}=\mathrm{k}^{\prime} \mathrm{I}_{0} /\left[\mathrm{RNX}_{2}\right]$, where $\mathrm{I}_{0}$ is the intensity of incident light. The addition of benzenesulphonamide, the product of photolysis or uranyl ion had no significant effect on the rate of photochemical decomposition. A slight decrease in the rate has been observed by the addition of $\mathrm{NaCl} / \mathrm{NaBr}$ to DCB / DBB solutions. The quantum yield $(\phi)$ for the photolytic decomposition has been computed. A suitable photolytic mechanism and a rate law consistent with the observed results have been proposed.
\end{abstract}

Keywords: Quantum yield, Photolysis, Dichloramine-B, Dibromamine-B, Aqueous acetic acid.

\section{Introduction}

Variety of reactions undergone by aromatic sulphonyl haloamines has attracted the attention of many investigators. The chemistry of these compounds is due to their ability to act as sources of halonium cations, hypohalite species and $\mathrm{N}$-anions, which act as both bases and nucleophiles. As a result, these reagents react with a wide range of functional groups effectively induce an array of molecular transformations. These reagents have been widely 
used as chlorinating / brominating / oxidizing agents in synthetic chemistry. Also, they are extensively used in the analytical determination of various organic and inorganic substrates. Although monohaloamines are soluble in water, dihaloamines are employed as redox titrants in non-aqueous or partially aqueous media.

Dichloramine-B and dibromamine-B are important members of these classes of compounds. Mechanistic investigation of semicarbazide ${ }^{1}$, thiosemicarbazide ${ }^{2}$ and its metal complexes ${ }^{3}$ with DCB has been reported. The reactions of unsaturated alcohols ${ }^{4}$, isoniazid $^{5}$, methionine and its complexes ${ }^{6}$, thiocyanate ion $^{7}$ and amino acids ${ }^{8}$ with DCB have been studied. Crystal and molecular structure studies of $\mathrm{DCB}^{9}$ have been reported. Analytical determination of cyanide ${ }^{10}$, thiocyanate ${ }^{11}$, thiosemicarbazide ${ }^{11}$ and various inorganic and organic compounds ${ }^{12}$ have been carried out with DBB. Bromination of hydrocarbon ${ }^{13}$, oxidation of ether ${ }^{14}$ and kinetics of reaction of tetrahydrofuran ${ }^{15}$ with DBB have been reported.

Photolysis of aqueous chloramine- $\mathrm{B}^{16}$ and bromamine- $\mathrm{B}^{17}$ under UV light radiation produces DCB and DBB respectively as major products. Conductometric study of the interaction of metal ion solutions with aqueous chloramine- $\mathrm{B}^{18}$ and bromamine$\mathrm{B}^{19}$ produces DCB and DBB respectively. In continuation of our work on photochemical decomposition of organic haloamines ${ }^{16,17,20,21}$ and $N$-halogenosuccinimides ${ }^{22}$, the present paper reports the quantum yield and kinetics of photochemical decomposition of DCB and DBB in aqueous acetic acid solutions.

\section{Experimental}

Dichloramine-B was prepared ${ }^{4}$ by passing chlorine through an aqueous solution of chloramine-B. Chloramine-B was prepare ${ }^{23}$ by passing pure chlorine for one hour through benzenesulphonamide dissolved in $4 \mathrm{M} \mathrm{NaOH}$ and heated to $70{ }^{\circ} \mathrm{C}$. The product was recrystallized from water. $30 \mathrm{~g}$ was dissolved in $500 \mathrm{~mL}$ of water and pure chlorine was bubbled through the solution for about $2 \mathrm{~h}$. The white precipitate of DCB formed was filtered off under suction, thoroughly washed with water and dried in a blackened vacuum desiccator (m.p. $74{ }^{\circ} \mathrm{C}$ ). The product was stored in brown bottles. The available chlorine was determined by iodometry (found $31.0 \%$; theoretical $31.4 \%$ ). Dibromamine-B was prepared ${ }^{24}$ by bromination of chloramine-B. Golden yellow precipitate of DBB obtained was washed with water and dried (m.p. $109{ }^{\circ} \mathrm{C}$ ). The available bromine was determined by iodometry (found 50.70\%; theoretical 50.74\%).

Dichloramine-B and dibromamine-B are only slightly soluble in water (DCB: $0.125 \mathrm{~g} \mathrm{~L}^{-1}$, DBB: $0.339 \mathrm{~g} \mathrm{~L}^{-1}$ at $30{ }^{\circ} \mathrm{C}$ ), but fairly soluble in glacial acetic acid, methanol and other common organic solvents. An approximately $0.1 \mathrm{~N}(0.025 \mathrm{M})$ solution of DCB and DBB were prepared in 1:1 (v/v) water-acetic acid. Solutions of DCB and DBB were standardized iodometrically and preserved in brown bottles to prevent photochemical decomposition. All other reagents were of AR grade. All solutions were prepared in doubly distilled water.

The UV irradiation was carried out with a Phillips (Holland) low-pressure mercury vapour lamp $(15 \mathrm{~W})$ and the wavelength of the light ${ }^{25}$ was $2537 \AA$. The experimental setup has been described elsewhere ${ }^{26}$. Exactly $10 \mathrm{~mL}$ of DCB / DBB solutions were taken in quartz cells and exposed to UV light radiation for various intervals of time. The photolytic decomposition was studied for more than two halflives. The extent of photochemical decomposition of DCB/DBB solutions was 
determined by iodometric titration of the experimental solution and comparison with a blank solution wherever necessary. The intensity of the light $\left(I_{0}\right)$ falling on the system was determined using uranyl oxalate actinometer ${ }^{25}$.

A SPECORD 50 UV-VIS spectrophotometer with $1.0 \mathrm{~cm}$ matched quartz cells was used in the UV spectral studies. A direct reading conductivity meter (ELICO CM 80) and a digital $\mathrm{pH}$ meter (ELICO L1 610) were used for conductance and $\mathrm{pH}$ measurements respectively. Regression analysis of the experimental data to obtain the regression coefficient, $r$, was performed using fx-570 MS scientific calculator.

\section{Results and Discussion}

The photochemical decomposition kinetics of DCB / DBB in aqueous acetic acid solutions has been studied in the concentration range of $0.01-0.0008 \mathrm{~mol} \mathrm{~L}^{-1}$. The results of photochemical decomposition of DCB and DBB solutions $\left(0.003 \mathrm{~mol} \mathrm{~L}^{-1}\right)$ at $\lambda=2537 \AA$ and the intensity of incident light, $\mathrm{I}_{\mathrm{o}}=1.458 \times 10^{16}$ quanta $^{-1}$ for DCB and $1.951 \times 10^{16}$ quanta $\mathrm{s}^{-1}$ for DBB are shown in Table 1 . The plots of $\log \left(\mathrm{V}_{\mathrm{o}} / \mathrm{V}_{\mathrm{t}}\right)$ versus time $(\mathrm{r}>0.998)$ are linear passing through the origin, where $\mathrm{V}_{\mathrm{o}}$ and $\mathrm{V}_{\mathrm{t}}$ refer to titre values of $\mathrm{Na}_{2} \mathrm{~S}_{2} \mathrm{O}_{3}$ solution at zero time and various intervals of time, $t$ in seconds respectively. The rate constant increases with increase in dilution of DCB / DBB at the temperature $29 \pm 0.5^{\circ} \mathrm{C}$. The results are given in Table 2. Plots of $\log k$ versus $\log \left[\mathrm{RNX}_{2}\right](\mathrm{r}>0.997$; Figure 1) are linear with the negative slopes of 1.02 (DCB) and 0.98 (DBB), indicating inverse-first order with respect to concentrations of DCB / DBB.

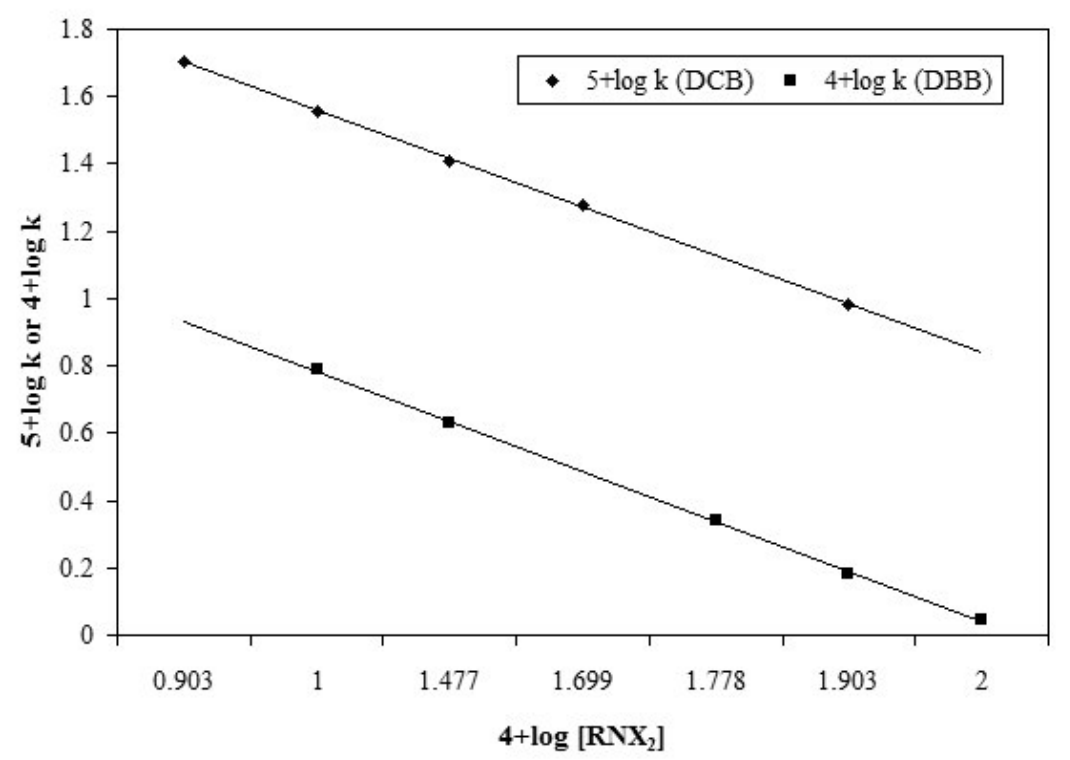

Figure 1. Plot of $4+\operatorname{logk}(\mathrm{DBB})$ or $5+\operatorname{logk}(\mathrm{DCB})$ versus $4+\log \left[\mathrm{RNX}_{2}\right]$.

At constant $\left[\mathrm{RNX}_{2}\right]$, wave length and temperature, the rate of photochemical decomposition of DCB and DBB solutions increases with increasing $\mathrm{I}_{\mathrm{o}}$ (Table 3). The plots of $\log \mathrm{R}\left(\mathrm{R}=\mathrm{k}\left[\mathrm{RNX}_{2}\right]\right)$ versus $\log \mathrm{I}_{\mathrm{o}}$ are linear $(\mathrm{r}>0.996$; Figure 2$)$ with slopes $1.01(\mathrm{DCB})$ and 1.02 (DBB) indicating a first-order dependence on the intensity of the incident light. 
Table 1. Photodecomposition of DCB and DBB in aqueous acetic acid solution with time $[D C B]=[D B B]=0.003 \mathrm{~mol} \mathrm{~L}^{-1} ; \mathrm{I}_{\mathrm{o}}(\mathrm{DCB})=1.458 \times 10^{16}$ quanta $^{-1}$ $\mathrm{I}_{\mathrm{o}}(\mathrm{DBB})=1.951 \times 10^{16}$ quanta s$^{-1} ; \lambda=2537 \AA ; \mathrm{T}=29 \pm 0.5^{\circ} \mathrm{C}$.

\begin{tabular}{ccc}
\hline Time $(\mathrm{s})$ & $*[\mathrm{DCB}] \times 10^{4}, \mathrm{~mol} \mathrm{~L}^{-1}$ & $*[\mathrm{DBB}] \times 10^{4}, \mathrm{~mol} \mathrm{~L}^{-1}$ \\
\hline 0 & $30.00 \pm 0.88$ & $30.00 \pm 0.89$ \\
300 & - & $26.90 \pm 0.70$ \\
600 & $28.70 \pm 0.80$ & $23.92 \pm 0.64$ \\
1200 & $25.41 \pm 0.66$ & $19.31 \pm 0.58$ \\
1800 & $23.50 \pm 0.62$ & $13.90 \pm 0.41$ \\
2400 & - & $10.83 \pm 0.30$ \\
3000 & $20.00 \pm 0.60$ & $8.14 \pm 0.24$ \\
3600 & - & $6.43 \pm 0.20$ \\
4200 & $16.70 \pm 0.46$ & - \\
6000 & $12.90 \pm 0.32$ & - \\
7800 & $10.22 \pm 0.30$ & - \\
9600 & $7.89 \pm 0.25$ & - \\
\hline
\end{tabular}

* Average of four replicates.

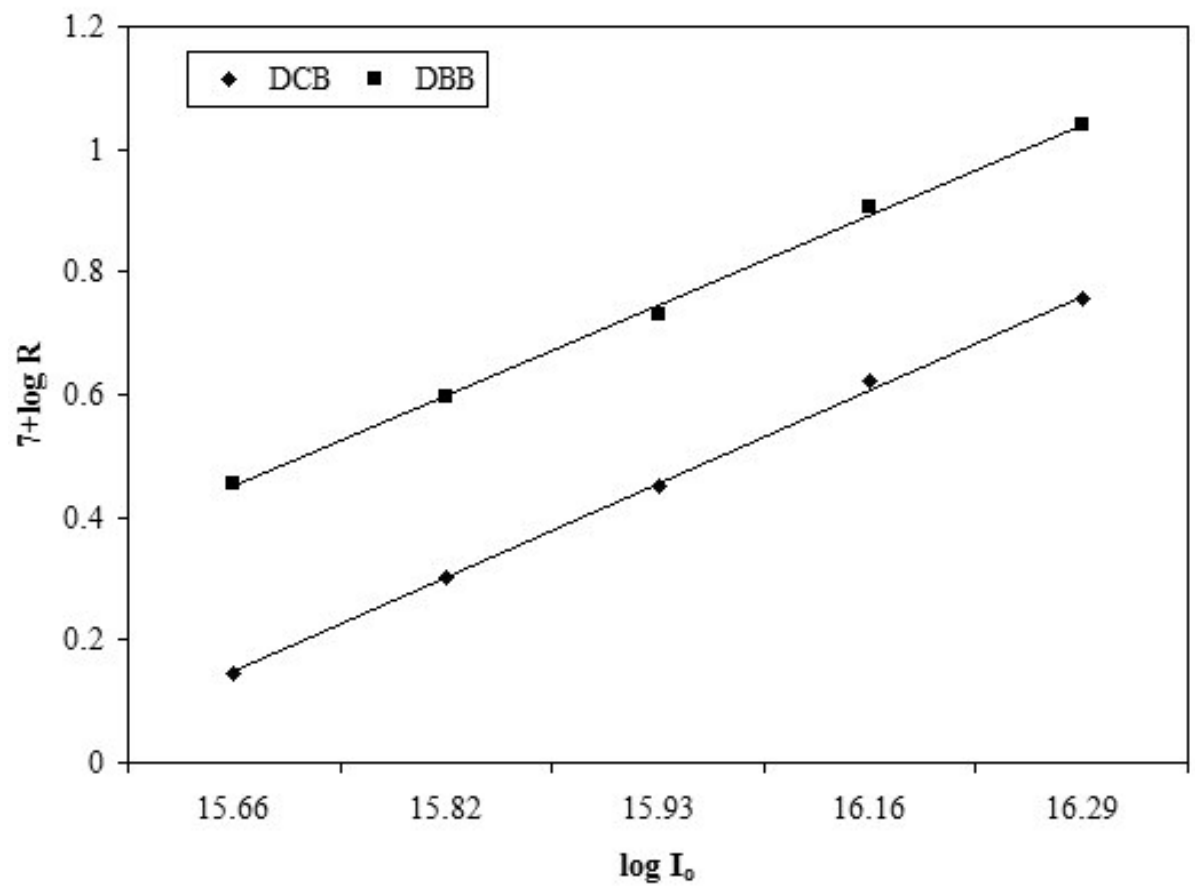

Figure 2. Plot of $7+\log R$ versus $\log \mathrm{I}_{0}$. 
Table 2. Photodecomposition of DCB and DBB in aqueous acetic acid medium at different concentrations $\lambda=2537 \AA ; \mathrm{I}_{\mathrm{o}}(\mathrm{DCB})=1.458 \times 10^{16}$ quanta $^{-1}$

$\mathrm{I}_{\mathrm{o}}(\mathrm{DBB})=1.951 \times 10^{16}$ quanta s$^{-1}, \mathrm{~T}=29 \pm 0.5^{\circ} \mathrm{C}$

\begin{tabular}{|c|c|c|c|}
\hline \multirow{2}{*}{$\begin{array}{c}{\left[\mathrm{RNX}_{2}\right] \times 10^{4}} \\
\mathrm{~mol} \mathrm{~L}^{-1}\end{array}$} & \multirow{2}{*}{$\begin{array}{c}{ }^{\mathrm{a}}[\mathrm{NaX}] \times 10^{2} \\
{ }^{\mathrm{b}}\left[\mathrm{UO}_{2}\left(\mathrm{NO}_{3}\right)_{2}\right] \times 10^{4} \\
{ }^{\mathrm{c}}[\mathrm{BSA}] \times 10^{4} \\
\mathrm{~mol} \mathrm{~L}^{-1}\end{array}$} & \multicolumn{2}{|c|}{$* \mathrm{k} \times 10^{4}, \mathrm{~s}^{-1}$} \\
\hline & & DCB & DBB \\
\hline 8.0 & - & $5.067 \pm 0.14$ & - \\
\hline 10.0 & - & $3.992 \pm 0.10$ & $12.162 \pm 0.31$ \\
\hline 30.0 & - & $1.396 \pm 0.03$ & $3.926 \pm 0.11$ \\
\hline 50.0 & - & $0.912 \pm 0.02$ & - \\
\hline 60.0 & - & - & $1.919 \pm 0.05$ \\
\hline 80.0 & - & $0.587 \pm 0.02$ & $1.439 \pm 0.03$ \\
\hline 100.0 & - & - & $1.107 \pm 0.02$ \\
\hline 30.0 & 2.0 (a) & $1.103 \pm 0.02$ & $3.664 \pm 0.09$ \\
\hline 30.0 & 3.0 (a) & $0.998 \pm 0.02$ & $3.705 \pm 0.09$ \\
\hline 30.0 & 4.0 (a) & $1.086 \pm 0.02$ & $3.641 \pm 0.09$ \\
\hline 30.0 & 5.0 (a) & $1.097 \pm 0.02$ & $3.699 \pm 0.09$ \\
\hline 30.0 & 5.0 (b) & $1.422 \pm 0.03$ & $3.899 \pm 0.12$ \\
\hline 30.0 & $10.0(b)$ & $1.408 \pm 0.03$ & $4.118 \pm 0.12$ \\
\hline 30.0 & $20.0(\mathrm{~b})$ & $1.391 \pm 0.03$ & $4.082 \pm 0.12$ \\
\hline 30.0 & $1.0(\mathrm{c})$ & $1.412 \pm 0.03$ & $3.905 \pm 0.10$ \\
\hline 30.0 & $3.0(\mathrm{c})$ & $1.404 \pm 0.03$ & $3.866 \pm 0.10$ \\
\hline 30.0 & $5.0(\mathrm{c})$ & $1.399 \pm 0.03$ & $3.849 \pm 0.10$ \\
\hline
\end{tabular}

* Average of four replicates.

Table 3. Effect of $\mathrm{I}_{0}$ on the rate of photodecomposition of DCB and DBB in aqueous acetic acid medium

\begin{tabular}{ccc}
{$[\mathrm{DCB}]=[\mathrm{DBB}]=0.003 \mathrm{~mol} \mathrm{~L}^{-1} ; \lambda=2537 \AA ⿻ \mathrm{\AA}=29 \pm 0.5^{\circ} \mathrm{C}$} \\
\hline \multirow{2}{*}{$\mathrm{I}_{\mathrm{o}} \times 10^{-16}$, quanta s $^{-1}$} & \multicolumn{2}{c}{$* \mathrm{R} \times 10^{7}, \mathrm{~mol} \mathrm{~L}^{-1} \mathrm{~s}^{-1}$} \\
\cline { 2 - 3 } & $\mathrm{DCB}$ & $\mathrm{DBB}$ \\
\hline 0.455 & $1.401 \pm 0.05$ & $2.844 \pm 0.10$ \\
0.658 & $2.007 \pm 0.07$ & $3.963 \pm 0.12$ \\
0.845 & $2.571 \pm 0.09$ & $5.394 \pm 0.15$ \\
1.458 & $4.179 \pm 0.12$ & $9.375 \pm 0.28$ \\
1.951 & $5.688 \pm 0.16$ & $12.378 \pm 0.34$ \\
\hline
\end{tabular}

* Average of four replicates. 
The average quantum yield $\left(\phi_{\mathrm{Av}}\right)$ for the disappearance of $\mathrm{RNX}_{2}$ at different concentrations with the intensity of absorbed light $\left(\mathrm{I}_{\mathrm{a}}\right)$ was calculated ${ }^{25}$ and the results are given in Table 4. The experiments carried out at $29 \pm 0.5{ }^{\circ} \mathrm{C}$ and $35 \pm 0.5{ }^{\circ} \mathrm{C}$ show that the temperature coefficients are $1.05\left(\mathrm{k}_{35}=1.466 \times 10^{-4} \mathrm{~s}^{-1}\right)$ and $1.08\left(\mathrm{k}_{35}=4.240 \times 10^{-4} \mathrm{~s}^{-1}\right)$ for $0.003 \mathrm{~mol} \mathrm{~L}^{-1} \mathrm{DCB}$ and DBB respectively. This shows the absence of any thermal reaction in the temperature range of $29-35^{\circ} \mathrm{C}$. A slight decrease in $\mathrm{k}$ on photolysis was noticed by the addition of $\mathrm{NaCl}$ and $\mathrm{NaBr}$ to DCB and DBB solutions respectively (Table 2).

Table 4. Average quantum yield $\left(\phi_{\mathrm{Av}}\right)$ for photolysis of DCB and DBB in aqueous acetic acid solutions

\begin{tabular}{|c|c|c|c|c|}
\hline \multirow{2}{*}{$\begin{array}{l}{\left[\mathrm{RNX}_{2}\right] \times 10^{4}} \\
\mathrm{~mol} \mathrm{~L}^{-1}\end{array}$} & \multicolumn{2}{|c|}{$\mathrm{I}_{\mathrm{a}} \times 10^{16}$, quanta $^{-1}$} & \multicolumn{2}{|c|}{$* \phi_{\mathrm{Av}}$} \\
\hline & DCB & $\mathrm{DBB}$ & DCB & DBB \\
\hline 8.0 & 0.924 & - & $0.196 \pm 0.02$ & - \\
\hline 10.0 & 1.037 & 1.302 & $0.187 \pm 0.02$ & $0.245 \pm 0.02$ \\
\hline 30.0 & 1.425 & 1.879 & $0.177 \pm 0.02$ & $0.246 \pm 0.02$ \\
\hline 50.0 & 1.455 & - & $0.172 \pm 0.02$ & - \\
\hline 60.0 & - & 1.948 & - & $0.302 \pm 0.02$ \\
\hline 80.0 & 1.458 & 1.951 & $0.158 \pm 0.02$ & $0.321 \pm 0.02$ \\
\hline 100.0 & - & 1.969 & - & $0.404 \pm 0.02$ \\
\hline
\end{tabular}

*Average of four replicates.

The addition of benzenesulphonamide (BSA) $\left(1 \times 10^{-4}-5 \times 10^{-4} \mathrm{~mol} \mathrm{~L}^{-1}\right)$, the product of photolysis and uranyl ion in the form of uranyl nitrate $\left(5 \times 10^{-4}-20 \times 10^{-4} \mathrm{~mol} \mathrm{~L}^{-1}\right)$ had no significant effect on the rate constant, $\mathrm{k}$ (Table 2). All these observations indicate no side reactions.

The $\mathrm{pH}$ measurements showed that, the solution of DCB / DBB become slightly acidic (DCB: from $\sim 1.26$ to $\sim 1.02$; DBB: from $\sim 1.62$ to $\sim 1.37$ ) upon irradiation and slightly yellow colouration was noticed after photolysis in the case of DBB. The conductivity of the solution slightly increases after photolysis (DCB: from $\sim 1.05 \mathrm{mS}$ to 1.42 $\mathrm{mS}$; DBB: from $\sim 1.04 \mathrm{mS}$ to $1.38 \mathrm{mS}$ ). No apparent change was noticed in the UV spectra of the products upon photolysis. Using the TLC technique (petroleum ether : chloroform : 1butanol $=2: 2: 1)$, only one spot was noticed in both cases with iodine as spray reagent $\left(\mathrm{R}_{\mathrm{f}}=\right.$ 0.88 ) indicating the formation of BSA in the irradiated solution of DCB / DBB. Liberation of free chlorine and bromine from photolytic solutions of DCB and DBB respectively has been noticed, which was tested by starch iodide paper. No complex mixture ${ }^{27}$ or resinous products $^{28}$ were observed.

Based on the observed results, the rate law for the photochemical decomposition of $\mathrm{RNX}_{2}$ in aqueous acetic acid solutions is given by the equation (1) below,

$$
-\frac{d\left[R N X_{2}\right]}{d t}=k \frac{I_{o}}{\left[R N X_{2}\right]}
$$

where $\mathrm{k}$ is a constant, $\mathrm{I}_{\mathrm{o}}$ is the intensity of the incident light and $\left[\mathrm{RNX}_{2}\right]$ indicates the concentration of DCB or DBB solutions. 
Dichloramine-B and dibromamine-B like dichloramine- $\mathrm{T}$ and dibromamine-T furnishes different reactive species in aqueous and partially aqueous solutions depending upon the $\mathrm{pH}$ of the medium ${ }^{29-32}$. The following equilibria exist in aqueous or partially aqueous solutions of $\mathrm{RNX}_{2}$ :

$$
\begin{array}{lll}
\mathrm{RNX}_{2}+\mathrm{H}_{2} \mathrm{O} & \rightleftharpoons & \mathrm{RNHX}^{2} \mathrm{HOX} \\
\mathrm{RNHX}+\mathrm{H}_{2} \mathrm{O} & \rightleftharpoons & \mathrm{RNH}_{2}+\mathrm{HOX} \\
\left.\mathrm{RNHX}^{+} \mathrm{H}^{+} \mathrm{X}\right)^{+} \\
\mathrm{RNX}_{2}+\mathrm{H}^{+} & \rightleftharpoons & \left(\mathrm{RNHX}_{2}\right)^{+} \\
\mathrm{ROX}^{+} \mathrm{H}^{+} & \rightleftharpoons & \left(\mathrm{H}_{2} \mathrm{OX}\right)^{+} \\
\left(\mathrm{RNH}_{2} \mathrm{X}\right)^{+}+\mathrm{H}_{2} \mathrm{O} & \rightleftharpoons \mathrm{RNH}_{2}+\left(\mathrm{H}_{2} \mathrm{OX}\right)^{+}
\end{array}
$$

where $\mathrm{R}=\mathrm{C}_{6} \mathrm{H}_{5} \mathrm{SO}_{2}$ and $\mathrm{X}=\mathrm{Cl}$ or $\mathrm{Br}$.

With the above results for the photolysis of DCB and DBB solutions and the equilibria in aqueous and partially aqueous solutions, the following photochemical reaction mechanism has been proposed for the decomposition of $\mathrm{RNX}_{2}$ solutions:

The first step is the activation process,

$$
\mathrm{RNX}_{2}+\mathrm{hv} \longrightarrow \quad\left(\mathrm{RNX}_{2}\right)^{*}
$$

The various propagation reactions could be represented as,

$$
\begin{aligned}
& \begin{array}{lll}
\left(\mathrm{RNX}_{2}\right)^{*}+\mathrm{H}_{2} \mathrm{O} & \longrightarrow & \mathrm{RNHX}+\mathrm{HOX} \\
\mathrm{RNHX}+\mathrm{H}_{2} \mathrm{O} & \longrightarrow & \mathrm{RNH}_{2}+\mathrm{HOX}
\end{array} \\
& \left(\mathrm{RNX}_{2}\right)^{*}+\mathrm{RNX}_{2} \longrightarrow \quad 2 \mathrm{RNX}_{2} \\
& \mathrm{HOX} \longrightarrow \mathrm{H} \dot{\mathrm{O}}+\dot{\mathrm{X}}
\end{aligned}
$$

and the termination steps can be written as,

$$
\begin{aligned}
& \dot{\mathrm{X}}+\dot{\mathrm{X}} \\
& \dot{\mathrm{O}} \mathrm{H}+\dot{\mathrm{O}} \mathrm{H} \\
& 2 \mathrm{H}_{2} \mathrm{O}_{2}
\end{aligned}
$$

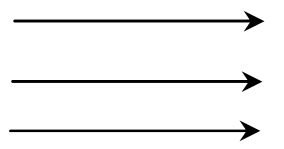

$\mathrm{X}_{2}$

$$
\begin{aligned}
& \mathrm{H}_{2} \mathrm{O}_{2} \\
& 2 \mathrm{H}_{2} \mathrm{O}+\mathrm{O}_{2}
\end{aligned}
$$

where $\mathrm{R}=\mathrm{C}_{6} \mathrm{H}_{5} \mathrm{SO}_{2}$ and $\mathrm{X}=\mathrm{Cl}$ or $\mathrm{Br}$.

The above photolytic mechanism is well supported by the fractional value of quantum yield $(\phi)$ observed for the photochemical decomposition, as not every excited species $\left(\mathrm{RNX}_{2}\right)^{*}$ will take part in the reaction. As the $\mathrm{RNX}_{2}$ solutions become more dilute, there is a greater penetration of light through the system and also the deactivation rate for the reaction $\left[\left(\mathrm{RNX}_{2}\right)^{*}+\mathrm{RNX}_{2} \rightarrow 2 \mathrm{RNX}_{2}\right]$ is smaller and this factor tends to increase the rate with dilution. However, the small variation in the quantum yield $(\phi)$ observed for the photolysis of $\mathrm{RNX}_{2}$ in the concentration range of $0.01-0.0008 \mathrm{~mol} \mathrm{~L}^{-1}$ is not significant and it is within the limits of the experimental error. Probably by using a high intensity of light $\left(>10^{18}\right.$ quanta $\left.\mathrm{s}^{-1}\right)$, more information could be obtained further on the photolysis of $\mathrm{RNX}_{2}$ solutions. Also, it is found that the rate of photolysis of DBB is nearly 2.2 times greater than that of DCB solution in the concentration range of $0.0008-0.01 \mathrm{~mol} \mathrm{~L}^{-1}$.

It may be concluded finally that the rate of disappearance of $\mathrm{RNX}_{2}$ is proportional to first power in $\mathrm{I}_{\mathrm{o}}$ and inverse first-order with respect to $\left[\mathrm{RNX}_{2}\right]$ in the photolysis experiment. The results with the addition of uranyl ion were unsuccessful for photosensitization. The main products formed are $\mathrm{RNH}_{2}$ and chlorine / bromine.

\section{References}

1. Gowda B T and Bhat J I, Indian J. Chem. 1988, 27A, 786. 
2. Gowda B T and Bhat J I, Tetrahedron 1987, 43(9), 2119.

3. Gowda B T and Bhat J I, Indian J. Chem. 1988, 27A, 597.

4. Yathirajan H S, Mahadevappa D S and Rangaswamy, Talanta 1980, 27, 52.

5. Yathirajan H S, Rangaswamy and Mahadevappa D S, J. Indian Chem. Soc. 1981, 58, 619.

6. Mahadevappa D S, Rangappa K S and Madegowda N M, Microchem J. 1983, 28, 235.

7. Gowda B T and Bhat J I, J. Indian Chem. Soc. 1988, 65, 512.

8. Rao D J M and Gowda B T, J. Indian Chem. Soc. 1992, 69, 642.

9. Lokanath N K, Sridhara M A, Shashidhara Prasad J, Yathirajan H S, Mohana K N and Rangappa K S, Mol. Cryst. Liq. Cryst. 1998, 319, 271.

10. Gowda B T, Sherigara B S and Mahadevappa D S, Microchem J. 1986, 34, 103.

11. Mahadevappa D S, Rangappa K S and Madegowda N M, Mirochem J. 1983, 28, 314.

12. Mahadevappa D S and Ahmed M S, Talanta 1979, 20, 500.

13. Suketaka T and Toshio O, Bull. Chem. Soc. Jpn. 1967, 40, 418.

14. Kamiya Y and Takemura S, Chem. Pharm. Bull. 1979, 21,1401.

15. Kamiya Y and Takemura S ,Chem. Pharm. Bull. 1972, 20, 2471.

16. Raju C R, Mohana K N, Yathirajan H S and Rangappa K S, Indian J. Chem. 2001, 40A, 613.

17. Mohana K N, Yathirajan H S, Ananda Murthy A S and Lokanatha Rai K M, Asian J. Chem. 1997, 9(4), 797.

18. Usha B N, Rangaswamy and Yathirajan H S, J. Indian Chem. Soc. 1984, 61, 812.

19. Mohana K N, Yathirajan H S and Rangaswamy, J. Indian Chem. Soc. 1997, 74, 765.

20. Mahadevappa D S and Ananda Murthy A S, Curr. Sci. 1974, 43, 246.

21. Yathirajan H S, Nagendra P, Mohana K N, Rai K M L, Rangappa K S and Ananda Murthy A S, Indian J. Chem. 2000, 39A, 1218.

22. Mohana K N and Bhandarkar P M R, Bulg. Chem. Communs. 2004, 36(4), 236.

23. Yathirajan H S, Rangaswamy and Mahadevappa D S, Collect. Czech. Chem. Communs. 1982, 47, 1826.

24. Yathirajan H S and Rangaswamy, Curr. Sci. 1981, 50, 677.

25. Calvert J G and Pitts J N, Photochemistry, John Wiley, New York, 1966, pp. 687, 787, 795.

26. Mahadevappa D S and Ananda Murthy A S, Bull. Kinetic India, 1982, 4, 6.

27. Dietzel R and Taufel K, Apoth. Ztg. 1929, 44, 989.

28. Ellis C and Wells A A, The Photochemical Action of Ultraviolet Rays, Reinhold, New York, 1941, p. 346.

29. Gowda B T and Mahadevappa D S, J. Chem. Soc. Perkin Trans. II, 1983, 323.

30. Bishop E and Jennings V J, Talanta 1958, 1, 197.

31. Hardy F F and Johnston J P, J. Chem. Soc. Perkin Trans. II, 1973, 742.

32. Gowda B T and Ramachandra P, J. Chem. Soc. Perkin Trans. II, 1989, 1067. 


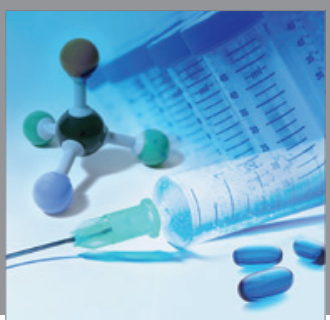

International Journal of

Medicinal Chemistry

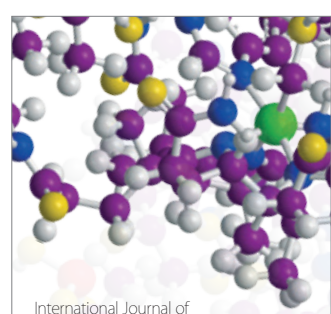

Carbohydrate Chemistry

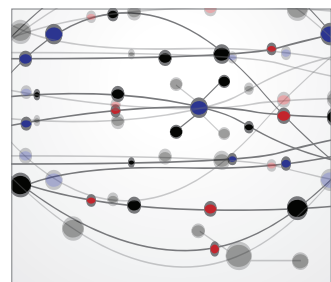

The Scientific World Journal
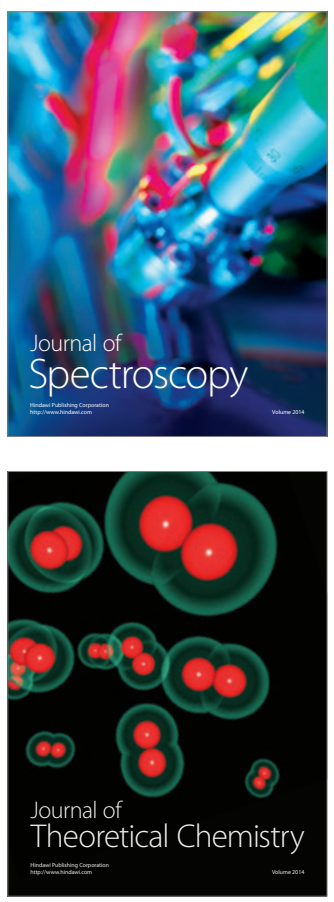
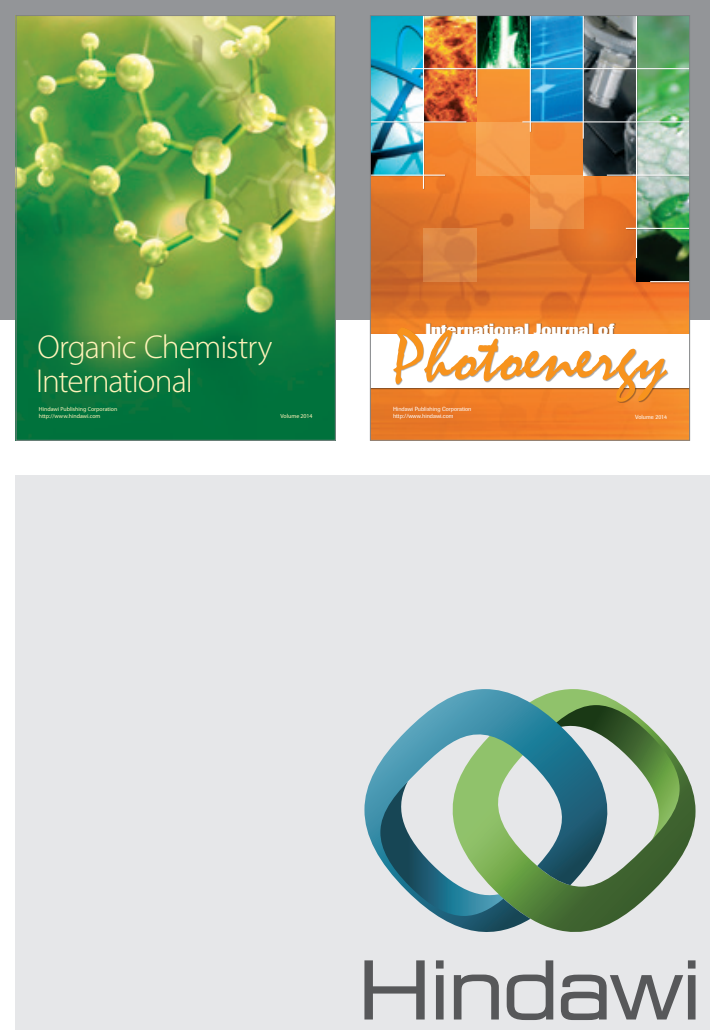

Submit your manuscripts at

http://www.hindawi.com
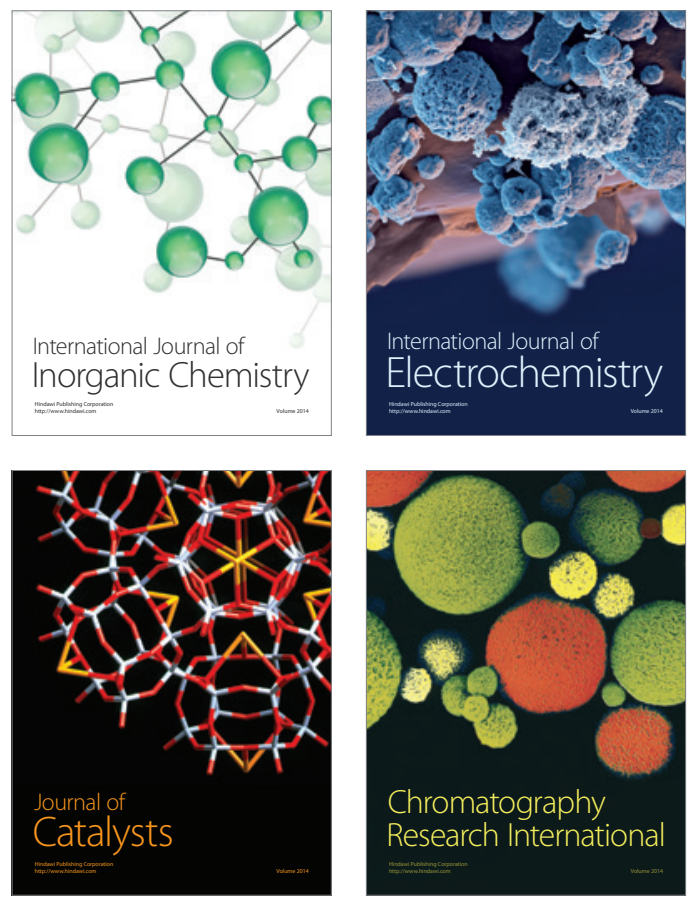
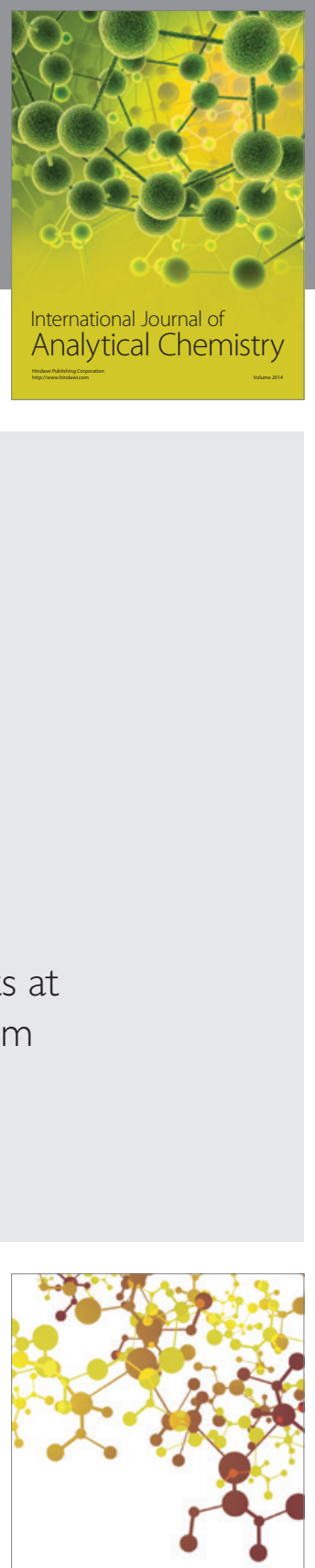

Journal of

Applied Chemistry
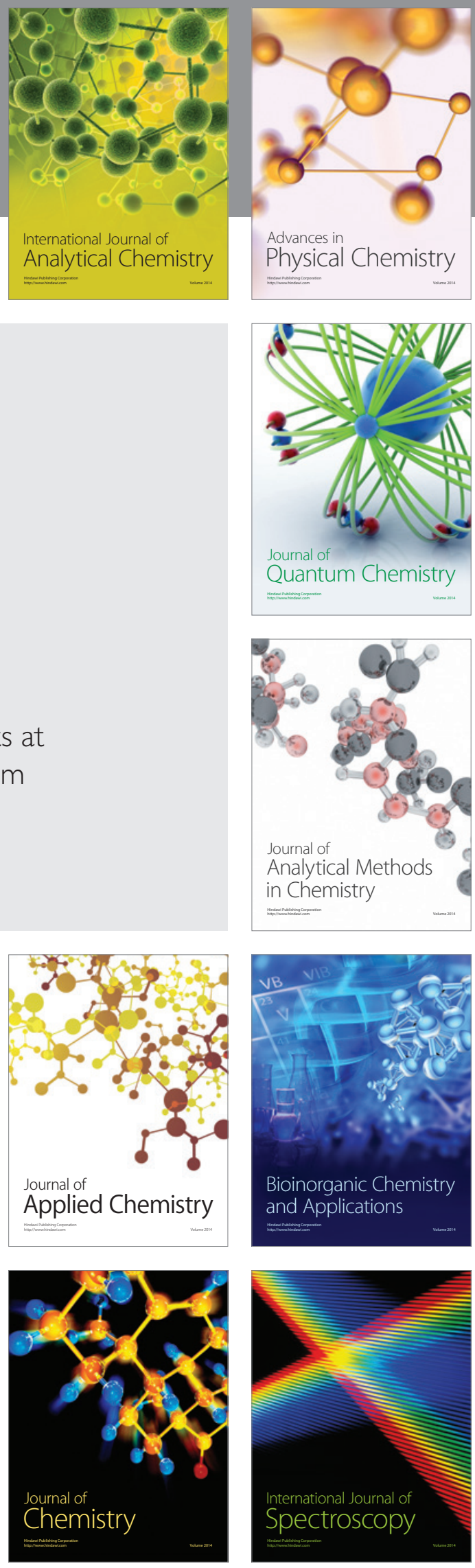